\title{
Beneficial effects of Huaiqihuang on hyperglycemia-induced MPC5 podocyte dysfunction through the suppression of mitochondrial dysfunction and endoplasmic reticulum stress
}

\author{
TING-XIA LI, JIAN-HUA MAO, LEI HUANG, HAI-DONG FU, SHUO-HUI CHEN, AI-MIN LIU and YU-QIN LIANG \\ Department of Nephrology, The Children's Hospital of Zhejiang University School of Medicine, \\ Hangzhou, Zhejiang 310003, P.R. China
}

Received March 15, 2016; Accepted March 1, 2017

DOI: $10.3892 / \mathrm{mmr} .2017 .6753$

\begin{abstract}
The present study was performed to investigate the effect of Huaiqihuang (HQH) on hyperglycemia (HG)-induced mitochondrial dysfunction and endoplasmic reticulum (ER) stress in MPC5 podocytes. The effects of HQH and HG on cell viability were assessed using an MTT assay. mRNA and protein expression levels were evaluated using reverse transcription-quantitative polymerase chain reaction and western blot analysis, respectively. Cell apoptosis was assessed using terminal deoxynucleotidyl transferase deoxyuridine triphosphate nick end labeling, whereas reactive oxygen species production and alterations in mitochondrial membrane potential were assessed using flow cytometry. DNA damage was evaluated using a comet assay. The results demonstrated that treatment of podocytes with $\mathrm{HQH}$ markedly suppressed the $\mathrm{HG}$-induced generation of reactive oxygen species. $\mathrm{HQH}$ also significantly improved mitochondrial membrane potential in podocytes exposed to HG. When the podocytes were treated with $\mathrm{HG}, \mathrm{Ca}^{2+}$ levels were significantly increased, compared with those in the control group, whereas treatment of the podocytes with $\mathrm{HQH}$ significantly reversed the $\mathrm{HG}$-induced upregulation of $\mathrm{Ca}^{2+}$ secretion. Treatment of the podocytes with $\mathrm{HQH}$ significantly reversed the $\mathrm{HG}$-induced upregulation of glucose-related protein 78 (GRP78) and $\mathrm{C} / \mathrm{EBP}$-homologous protein, which were used as indicators of ER stress. Furthermore, GRP78 loss-of-function attenuated HG-induced podocyte dysfunction, including cell apoptosis and DNA damage. In conclusion, beneficial effects of $\mathrm{HQH}$ on HG-induced MPC5 podocyte dysfunction were observed, and occurred through the suppression of mitochondrial dysfunction and ER stress.
\end{abstract}

Correspondence to: Dr Jian-Hua Mao, Department of Nephrology, The Children's Hospital of Zhejiang University School of Medicine, 57 Zhugan Lane, Hangzhou, Zhejiang 310003, P.R. China

E-mail: mao_jhch@163.com

Key words: mitochondrial dysfunction, endoplasmic reticulum stress, podocyte, Huaiqihuang

\section{Introduction}

Diabetic nephropathy (DN) is an important endocrine metabolic dysfunctional disease and the leading cause of end-stage renal disease worldwide (1). Increasing evidence indicates that injury, detachment, apoptosis and loss of podocytes are observed in humans with DN and in DN animal models (2-4). Podocytes are key in maintaining the integrity of the glomerular filtration barrier, together with mesangial cells, and have been reported to be important for the progression of diabetic kidney disease (5). In patients with type I and II diabetes mellitus, the density of podocytes is significantly reduced in those who have had the diabetes for a short duration prior to the onset of microalbuminuria (6). A correlation between the rate of albumin excretion and the reduction in podocyte number has been demonstrated in rats with streptozotocin-induced diabetes mellitus (7). In addition, high glucose $(\mathrm{HG})$ provokes adhesion capacity and phenotypic alterations in cultured podocytes (8). Taken together, these data indicate that podocyte injury is closely associated with hyperglycemia. Although there is considerable evidence suggesting that chronic hyperglycemia is the primary cause of podocyte injury, the underlying molecular mechanisms of hyperglycemia-induced podocyte injury remain to be elucidated.

Endoplasmic reticulum (ER) is a central organelle engaged in lipid synthesis, protein folding and maturation (9). A variety of toxic insults, including hypoxia (10), glucocorticoids (11) and HG (12), can disturb ER function, and result in ER stress. There is increasing evidence that ER stress is crucial in the regulation of apoptosis (13), with a previous study reporting that ER stress is triggered in angiotensin II-treated podocytes (14). In addition, palmitate induces ER calcium depletion and apoptosis in mouse podocytes following mitochondrial oxidative stress (9), and HG induces the apoptosis of podocytes through ER stress in vivo and in vitro $(15,16)$. These results suggest that ER stress is involved in the pathogenesis of podocyte dysfunction and is being recognized as an emerging target for DN therapy.

Huaiqihuang (HQH) is predominantly composed of Trametes robiniophila Murr, Fructus Lycii and Polygonatum sibiricum, and has been widely used for the 
treatment of primary nephrotic syndrome (17). In renal tissues of rats with adriamycin-induced nephrosis, HQH can maintain the integrity of the slit diaphragm in podocytes, alleviate lesions of the glomerular filtration membrane, and decrease proteinuria by upregulating the expressions of nephrin and podocin (18). However, the protective effect of $\mathrm{HQH}$ in hyperglycemia-induced MPC5 podocyte dysfunction remains to be fully elucidated. To the best of our knowledge, the present study is the first to attempt to determine the protective effect of HQH in hyperglycemia-induced MPC5 podocytes. The data provided evidence that $\mathrm{HQH}$ attenuated hyperglycemia-induced reactive oxygen species (ROS) generation and ER stress in MPC5 podocytes.

\section{Materials and methods}

Cell culture. MPC5 podocytes were obtained from the Cell Resource Center, Shanghai Institutes for Biological Sciences (Shanghai, China), and maintained in RPMI-1640 (Invitrogen; Thermo Fisher Scientific, Inc., Waltham, MA, USA) supplemented with $10 \%$ FBS (Invitrogen; Thermo Fisher Scientific, Inc.) at $37^{\circ} \mathrm{C}$ in a humidified incubator (Thermo Fisher Scientific, Inc.), $5 \% \mathrm{CO}_{2}, 95 \%$ air atmosphere. RPMI-1640 medium containing high glucose (HG; $30 \mathrm{mM}$ D-glucose) or normal glucose (5 mM D-glucose) was used.

Cell viability detection using 3-(4,5-dimethylthiazol-2-yl)2,5-diphenyltetrazolium bromide (MTT). The proliferation of MPC5 podocytes $\left(1 \times 10^{5}\right)$ was monitored using an MTT Cell Proliferation/Viability Assay kit (R\&D Systems, Inc., Minneapolis, MN, USA) according to the manufacturer's protocol.

Caspase-3 activity. Activity of caspase-3 was determined using the caspase-3 activity assay kit (cat. no. C1116; Beyotime Institute of Biotechnology, Haimen, China), according to the manufacturer's protocol. Briefly, $\sim 1 \times 10^{6}$ cells were incubated for $30 \mathrm{~min}$ at $0^{\circ} \mathrm{C}$ in $2 \mathrm{ml}$ of lysis buffer, containing 25 mM Hepes, pH 7.5 (Sigma-Aldrich; Merck KGaA, Darmstadt, Germany), 5 mM EDTA (Sigma-Aldrich; Merck KGaA), 1 mM EGTA (Sigma-Aldrich; Merck KGaA), $5 \mathrm{mM} \mathrm{MgCl} 2$ (Thermo Fisher Scientific, Inc.), $10 \mathrm{mM}$ Sucrose (Thermo Fisher Scientific, Inc.), $5 \mathrm{mM}$ dithiothreitol (DTT; Sigma-Aldrich; Merck KGaA), 1\% 3-[-(3-chloramidopropyl) dimethylammonio]-1-propanesulfonic acid (CHAPS; Sigma-Aldrich; Merck KGaA), protease inhibitor cocktail (10 $\mu \mathrm{l} / \mathrm{ml}$; Sigma-Aldrich; Merck KGaA), and $1 \mathrm{mM}$ PMSF (Sigma-Aldrich; Merck KGaA). Cell lysates were freeze/thawed three times and centrifuged at $12,000 \mathrm{x} \mathrm{g}$ for $60 \mathrm{~min}$ at $4^{\circ} \mathrm{C}$. The supernatants were collected and incubated with caspase- 3 substrate in $\mathrm{PBS}$ for $2 \mathrm{~h}$ at $37^{\circ} \mathrm{C}$. The release of p-nitroaniline was measured at $405 \mathrm{~nm}$ using an ELISA reader (MD SpectraMax M5; Molecular Devices LLC, Sunnyvale, CA, USA) according to the manufacturer's protocol. The results indicated the percentage change in activity compared with the untreated control.

Terminal deoxynucleotidyl transferase-mediated deoxyuridine triphosphate nick end labeling (TUNEL) assay. Quantitative assessment of the apoptotic cells was performed using the
TUNEL method, which examines DNA-strand breaks during apoptosis, using a BD ApoAlert ${ }^{\mathrm{T}}$ DNA Fragmentation Assay kit (BD Biosciences, Franklin Lakes, NJ, USA). The cells were trypsinized, fixed with $4 \%$ paraformaldehyde for $30 \mathrm{~min}$ at room temperature and permeabilized with $0.1 \%$ Triton-X-100 in $0.1 \%$ sodium citrate for $5 \mathrm{~min}$ at room temperature. Following washing with PBS three times, the cells $\left(1 \times 10^{5}\right)$ were incubated with the reaction mixture for $60 \mathrm{~min}$ at $37^{\circ} \mathrm{C}$. The cells were immediately analyzed using FACScan flow cytometry and the CellQuest ${ }^{\mathrm{TM}}$ software version 5.1 (BD Biosciences).

Measurement of ROS. The generation of ROS in cells was evaluated with a fluorometric assay using intracellular oxidation of dichlorodihydrofluorescein diacetate (DCFH-DA). The cells $\left(2 \times 10^{6}\right)$ were incubated in a 6 -well plate for $24 \mathrm{~h}$ at $37^{\circ} \mathrm{C}$ for stabilization, and were then detected and analyzed using flow cytometry (BD Biosciences.).

Measurement of $\mathrm{H}_{2} \mathrm{O}_{2}$, malondialdehyde (MDA) and permea bility. An Amplex Red assay (Thermo Fisher Scientific, Inc.) was used to measure $\mathrm{H}_{2} \mathrm{O}_{2}$ levels, which were measured at an excitation wavelength of $560 \mathrm{~nm}$ and emission detection wavelength of $590 \mathrm{~nm}$ using an ELISA reader (MD SpectraMax M5; Molecular Devices LLC) according to the manufacturer's protocol. A Biochemical Analysis kit (Nanjing Jiancheng Bioengineering Institute, Nanjing, China) was used for the measurement of MDA, according to manufacturer's protocol. The permeability of the podocytes was measured, as described previously (19).

Detection of $\mathrm{Ca}^{2+}$ concentrations. The MPC5 podocytes were plated and treated in 12-well plates, and were incubated to detect changes in $\mathrm{Ca}^{2+}$ levels. The cells were harvested and washed with PBS twice, and resuspended in Indo 1/AM (3 $\mu \mathrm{g} / \mathrm{ml}$ ) at $37^{\circ} \mathrm{C}$ for $30 \mathrm{~min}$, followed by analysis using flow cytometry (BD Biosciences).

Determination of mitochondrial membrane potential. The mitochondrial membrane potential was assessed using a fluorometric probe $\left(\mathrm{DiOC}_{6}\right.$; Molecular Probes; Thermo Fisher Scientific, Inc.). Briefly, cells $\left(2 \times 10^{6}\right)$ were plated in 6-well culture dishes. On reaching confluence, the cells were treated with $\mathrm{HG}(30 \mathrm{mM})$ or $\mathrm{HQH}(0,0.2,1$ or $2 \mathrm{mg} / \mathrm{ml})$ for $24 \mathrm{~h}$ at $37^{\circ} \mathrm{C}$. Following incubation, the cells were stained with $\mathrm{DiOC}_{6}$ $(40 \mathrm{nM})$ for $15 \mathrm{~min}$ at $37^{\circ} \mathrm{C}$. The cells were then collected, washed twice in PBS and analyzed using FACScan flow cytometry (BD Biosciences).

Small interfering RNA (siRNA) transfection. The siRNAs against glucose-related protein 78 (GRP78) and scrambled siRNA were obtained from GE Dharmacon (Lafayette, CO, USA). The cells $\left(1 \times 10^{5}\right)$ were transfected with the siRNAs (at a final concentration of $100 \mathrm{nM}$ ) using Lipofectamine 2000 (Invitrogen; Thermo Fisher Scientific. Inc.) according to the manufacturer's protocol. Sequences of the siRNAs used were as follows: si-GRP78, sense 5'-AAGGUUACCCAUGCA GUUGTT-3', antisense 5'-CAACUGCAUGGGUAACCU UTT-3'; and scrambled siRNA, sense 5'-UUCUGCGAUGCU GUCACGUAT-3' and antisense 5'-ACCUGACUCGAUCGC AGAAAT-3'. 
Comet assay. Briefly, fully frosted slides were precoated at each end with $100 \mathrm{ml}$ of $0.8 \%$ agarose in PBS (pH 7.4), covered with a $22 \times 22 \mathrm{~mm}$ glass coverslip and left at room temperature for $20 \mathrm{~min}$. Subsequently, $30 \mathrm{ml}$ of the cell culture was mixed with $70 \mathrm{ml}$ of $1 \%$ low-melting point agarose in PBS and maintained at $42^{\circ} \mathrm{C}$ on a dry-bath incubator. The mixture was immediately spread onto each end of a precoated slide and covered with a fresh glass coverslip. Images of the comets were captured with an Olympus microscope (Olympus Corporation, Tokyo, Japan) equipped with a CCD camera connected to the fluorescent microscope.

Reverse transcription-quantitative polymerase chain reaction $(R T-q P C R)$. RNA extraction from the MPC5 podocytes was performed using TRIzol ${ }^{\circledR}$ reagent according to the manufacturer's protocol (Invitrogen; Thermo Fisher Scientific, Inc.). Total RNA was reverse transcribed into cDNA, using a $20 \mu \mathrm{l}$ reaction mixture containing $4 \mu \mathrm{g}$ of total RNA using M-MLV Reverse Transcriptase (Invitrogen; Thermo Fisher Scientific, Inc.) and oligo dT (15) primers (Fermentas; Thermo Fisher Scientific, Inc.) according to the manufacturer's protocol. The first strand cDNAs served as the template for PCR. The reaction mixture $(25 \mu \mathrm{l})$ included $12.5 \mu \mathrm{l} \mathrm{iQ}^{\mathrm{TM}}$ SYBR-Green Supermix (Bio-Rad Laboratories, Inc., Hercules, CA, USA), $1 \mu \mathrm{l} \mathrm{cDNA}, 300 \mathrm{nM}$ of each primer, and diethyl pyrocarbonate-treated water to a final volume of $25 \mu \mathrm{l}$. PCR was performed using a DNA engine (ABI 7300; Thermo Fisher Scientific, Inc.). Amplification conditions were as follows: Initial denaturation at $95^{\circ} \mathrm{C}$ for $3 \mathrm{~min}$, followed by $30-40$ cycles of denaturation at $95^{\circ} \mathrm{C}$ for $15 \mathrm{sec}$, annealing at $56^{\circ} \mathrm{C}$ for $20 \mathrm{sec}$ and extension at $72^{\circ} \mathrm{C}$ for $20 \mathrm{sec}$. PCR was performed using the following primers: Nephrin, forward 5'-AGCTCGTGTCTCCCAGAGT-3', reverse 5'-CGT TCACGTTTGCAGAGATGT-3'; GRP78, forward 5'-AAC CCAGATGAGGCTGTAGCA-3', reverse 5'-ACATCA AGCAGAACCAGGTCAC-3'; C/EBP-homologous protein (CHOP), forward 5'-CCAGCAGAGGTCACAAGCAC-3', reverse 5'-CGCACTGACCACTCTGTTTC-3'; and GAPGH, forward 5'-GGTGGAGGTCGGGAGTCAACGGA-3' and reverse 5'-GAGGGATCTCGCTCCTGGAGGA-3'. Relative expression levels of the target genes were normalized to GAPDH, using the $2^{-\Delta \Delta \mathrm{Cq}}$ method (20).

Western blot analysis. The MPC5 podocytes were homo genized in NP-40 buffer, followed by 5-10 min boiling and centrifugation at $12,000 \mathrm{xg}$ for $10 \mathrm{~min}$ at $4^{\circ} \mathrm{C}$ to obtain the supernatants. Protein concentrations were determined using the Bicinchoninic Acid kit for Protein Determination (cat. no. BCA1-1KT; Sigma-Aldrich; Merck KGaA). Equal amounts of extracted protein samples $(30 \mu \mathrm{g})$ were separated by $10 \%$ SDS-PAGE and transferred onto nitrocellulose membranes (Bio-Rad Laboratories, Inc.). Following saturation with $5 \%$ non-fat dry milk in TBS containing $0.1 \%$ Tween-20 (TBST) for $2 \mathrm{~h}$ at room temperature and two washes with PBS, the membranes were incubated with the following primary antibodies at $4{ }^{\circ} \mathrm{C}$ overnight: Anti-nephrin (cat. no. sc-377246; 1:1,000), anti-GRP78 (cat. no. sc-376768; 1:1,000), anti-cleaved-caspase-3 (cat. no. sc-271028; 1:1,000), anti- $\beta$-actin (cat. no. sc-130065; 1:2,000) from Santa Cruz Biotechnoogy, Inc. (Dallas, TX, USA); and anti-CHOP (cat. no. AC532; 1:1,000) from Beyotime Institute of Biotechnology. Following three washes with TBST, the membranes were incubated for $2 \mathrm{~h}$ at $37^{\circ} \mathrm{C}$ with donkey anti-mouse horseradish peroxidase-conjugated immunoglobulin G (cat. no. sc-2096; 1:10,000) from Santa Cruz Biotechnology, Inc. Subsequently, membranes were washed three times with TBST and visua lized using an enhanced chemiluminescence kit (Thermo Fisher Scientific, Inc.). Blots were semi-quantified using densitometric analysis with the Quantity One ${ }^{\circledR}$ software version 4.5 (Bio-Rad Laboratories, Inc.) and normalized to $\beta$-actin expression to correct for unequal loading.

Statistical analysis. The data from experiments are reported as the mean \pm standard deviation for each group. All statistical analyses were performed using GraphPad Prism software version 4.0 (GraphPad Software, Inc., La Jolla, CA, USA). Inter-group differences were analyzed using one-way analysis of variance, followed by a post hoc Tukey's test for multiple comparisons. $\mathrm{P}<0.05$ was considered to indicate a statistically significant difference.

\section{Results}

$H Q H$ protects against $H G$-induced podocyte apoptosis and dysfunction. To investigate the potential apoptotic effects of HG in podocytes, the present study first examined the effect of HG on cell survival using an MMT assay. The podocytes were treated with $30 \mathrm{mM} \mathrm{HG}$ for various periods of time, and the results showed that $\mathrm{HG}$ reduced cell viability in a time-dependent manner, compared with that of the control group (Fig. 1A). Determination of the cytotoxic effect of $\mathrm{HQH}$ was imperative prior to further experiments. The viability of podocytes following incubation with different concentrations of HQH for $24 \mathrm{~h}$ was determined using the MTT assay. The podocytes retained almost the same viability when exposed to $\mathrm{HQH}$ at concentrations of $0-2 \mathrm{mg} / \mathrm{ml}$, whereas concentrations of $\mathrm{HQH}>20 \mathrm{mg} / \mathrm{ml}$ markedly altered cell viability (Fig. 1B). Therefore, concentrations of $\mathrm{HQH}<2 \mathrm{mg} / \mathrm{ml}$ were suitable for the selective pharmacological action of the drug without any interference of normal cell function. The podocyte protein, nephrin, is essential for maintaining the filtration barrier of the kidney and preventing albuminuria (21). As shown in Fig. 1C and $\mathrm{D}$, the results indicated that, compared with the NG-treated group, HG treatment of podocytes exerted a marked decrease in the mRNA and protein levels of nephrin, whereas $\mathrm{HQH}$ at concentrations of 1 and $2 \mathrm{mg} / \mathrm{ml}$ significantly reversed this effect. Subsequently, TUNEL staining was performed to examine the effect of the downregulation of $\mathrm{HQH}$ on podocyte cell apoptosis, and the percentage of TUNEL-positive (apoptotic) cells was calculated. As shown in Fig. 1E, the percentage of apoptotic cells induced by HG decreased when the podocytes were exposed to $\mathrm{HQH}$ at concentrations of 1 and $2 \mathrm{mg} / \mathrm{ml}$.

HQH inhibits HG-induced ROS and mitochondrial dysfunction in podocytes. The effects of $\mathrm{HQH}$ on HG-induced ROS and mitochondrial dysfunction were determined in podocytes (Fig. 2). To identify the role of ROS in podocyte injury, ROS concentrations were measured by flow cytometry using DCFH-DA. Compared with untreated podocytes, treatment with 
A

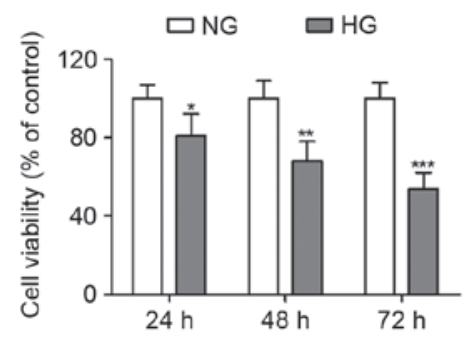

D

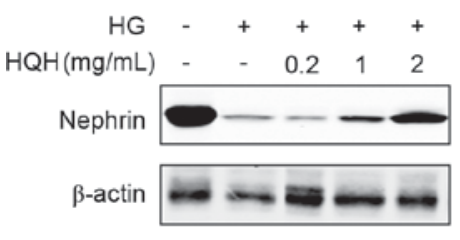

B
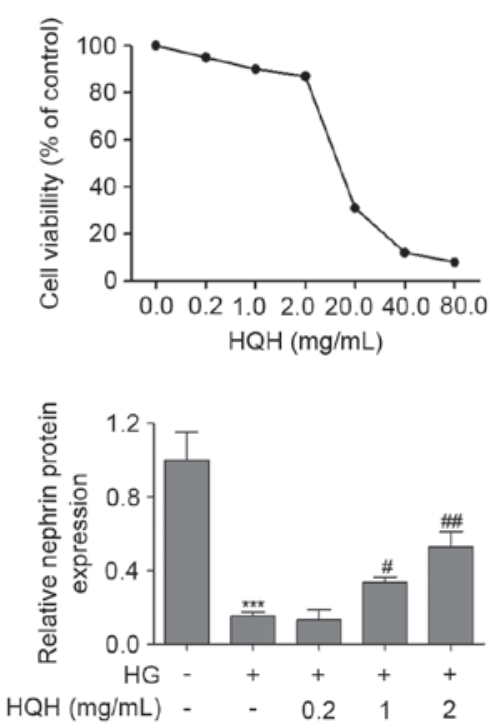

C

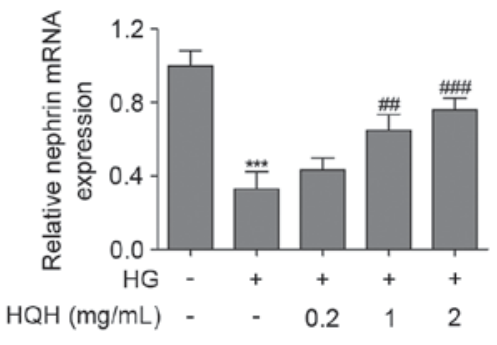

$\mathrm{E}$

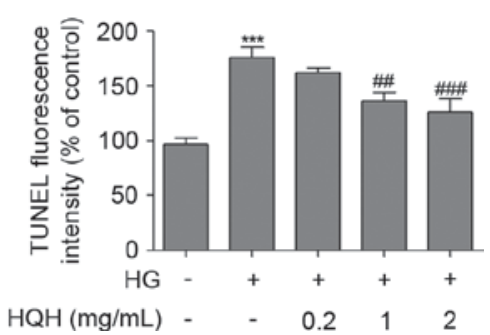

Figure 1. HQH protects against HG-induced podocyte apoptosis and dysfunction. (A) MPC5 podocytes were incubated with HG (30 mM) and HQH, and the cell viability was examined using an MTT assay. (B) Effect of HQH on the viability of podocytes (1x10 4 cells/well) incubated with $\mathrm{HQH}$ of different concentrations for $24 \mathrm{~h}$. Cell viability was determined using the MTT assay. The (C) mRNA and (D) protein expression levels of nephrin were measured using reverse transcription-polymerase chain reaction and western blot analyses, respectively, following $24 \mathrm{~h}$ treatment. (E) TUNEL-positive (apoptotic) cells were measured using flow cytometry following $24 \mathrm{~h}$ treatment. Values are expressed as the mean \pm standard deviation $\left(\mathrm{n}=3\right.$ in each group). ${ }^{*} \mathrm{P}<0.05,{ }^{* * *} \mathrm{P}<0.01$ and ${ }^{* * *} \mathrm{P}<0.001$, vs. control group; ${ }^{\#} \mathrm{P}<0.05,{ }^{\# \#} \mathrm{P}<0.01$ and ${ }^{\# \# /} \mathrm{P}<0.001$, vs. HG only treatment group. HG, high glucose; HQH, Huaiqihuang; NG, normal glucose; MTT, 3- (4,5-dimethylthiazol-2-yl) -2,5-diphenyltetrazolium bromide; TUNEL, terminal deoxynucleotidyl transferase-mediated deoxyuridine triphosphate nick end labeling.

A
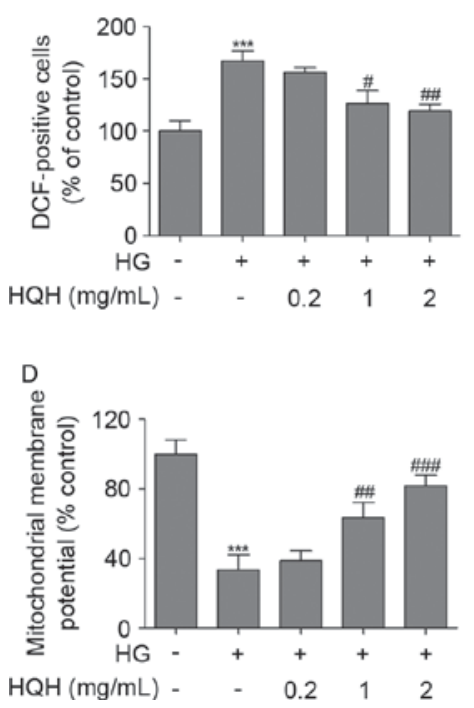

B

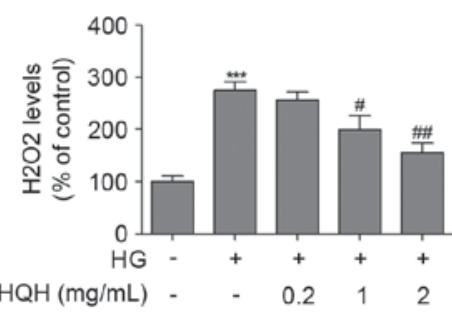

$\mathrm{E}$

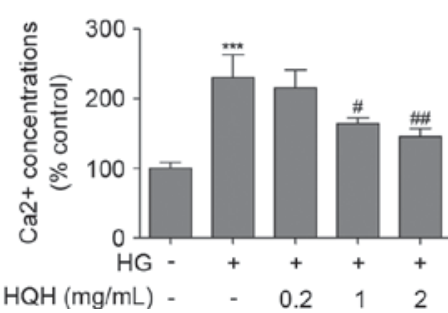

$\mathrm{C}$

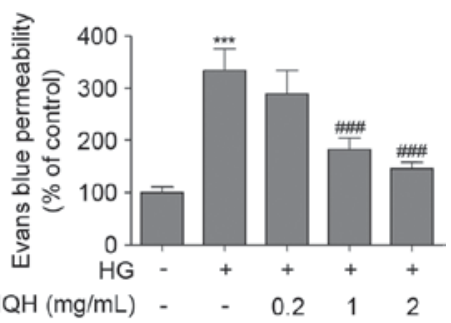

$\mathrm{F}$

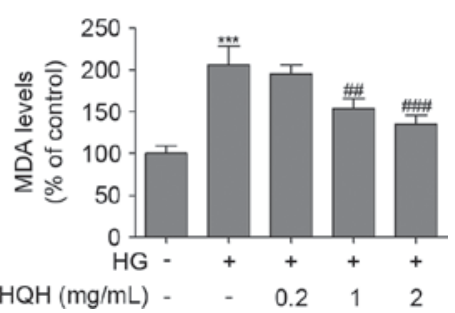

Figure 2. HQH inhibits HG-induced ROS and mitochondrial dysfunction in podocytes. (A) Intracellular ROS production was measured according to changes in the fluorescence intensity of DCF, the oxidized derivative of DCF-DA, following $12 \mathrm{~h}$ treatment. (B) $\mathrm{H}_{2} \mathrm{O}_{2}$ was measured using an Amplex Red assay following $24 \mathrm{~h}$ treatment. (C) Effects of HG and HQH on permeability in MPC5 podocytes was measured over $24 \mathrm{~h}$. MPC5 podocytes were incubated with $\mathrm{HG}(30 \mathrm{mM})$ or $\mathrm{HQH}$ for $24 \mathrm{~h}$, and the (D) mitochondrial membrane potential and (E) release of $\mathrm{Ca}^{2+}$ were examined using flow cytometry. (F) MDA levels were measured following exposure of MPC5 podocytes to HG $(30 \mathrm{mM})$ or HQH for $24 \mathrm{~h}$. Values are expressed as the mean \pm standard deviation $(\mathrm{n}=3$ in each group). ${ }^{* * *} \mathrm{P}<0.001$, vs. control group; ${ }^{\#} \mathrm{P}<0.05$, ${ }^{\# \#} \mathrm{P}<0.01$ and ${ }^{\# \# \#} \mathrm{P}<0.001$, vs. HG only treatment group. HG, high glucose; HQH, Huaiqihuang; DCF-DA, dichlorodihydrofluorescein diacetate; MDA, malondialdehyde.

HG caused a significant increase in intracellular ROS generation. Treatment of the podocytes with $\mathrm{HQH}$ at concentrations of 1 and $2 \mathrm{mg} / \mathrm{ml}$ markedly suppressed the HG-induced ROS generation (Fig. 2A). In addition, treatment of the podocytes with $\mathrm{HQH}$ significantly reversed the HG-induced upregulation in the production of $\mathrm{H}_{2} \mathrm{O}_{2}$ (Fig. 2B), permeability (Fig. 2C) and
MDA (Fig. 2F) in podocytes. To further examime whether HG-induced cell apoptosis was mediated through mitochondrial dysfunction, the present study determined mitochondrial membrane potential using the mitochondria-sensitive dye, $\mathrm{DiOC}_{6}$, with flow cytometry. As shown in Fig. 2D, treatment of podocytes with $\mathrm{HG}$ led to the loss of mitochondrial membrane 
A
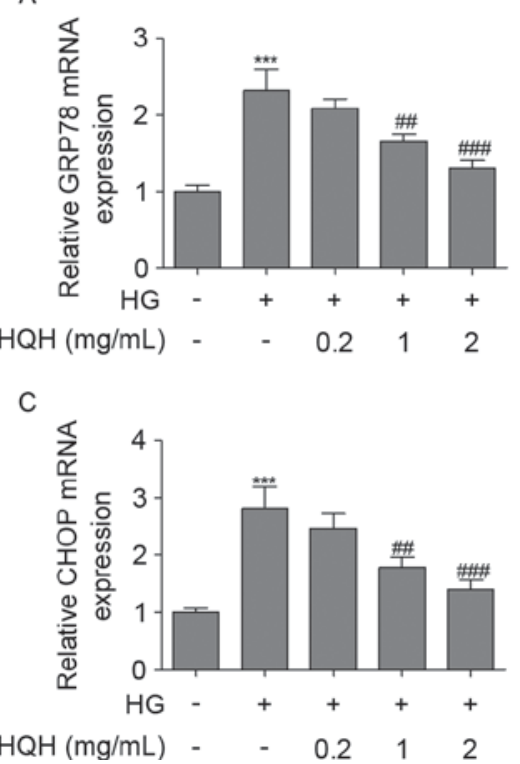

B

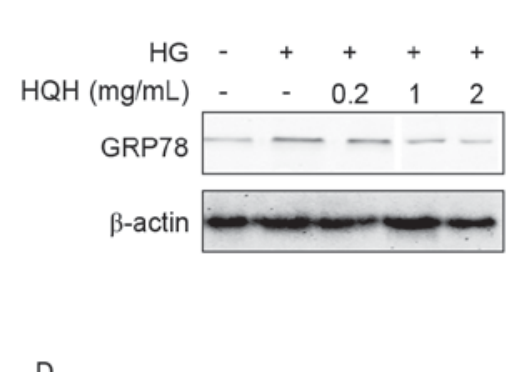

D

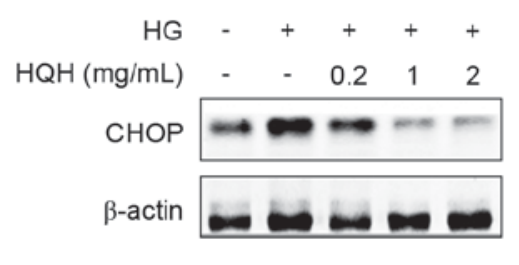

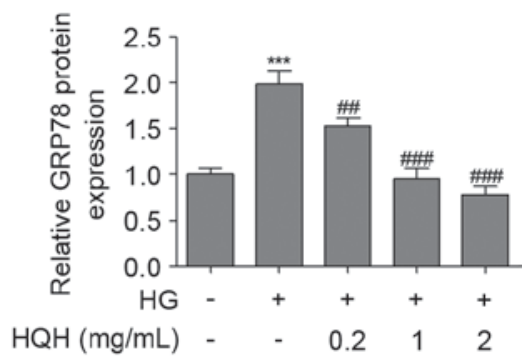

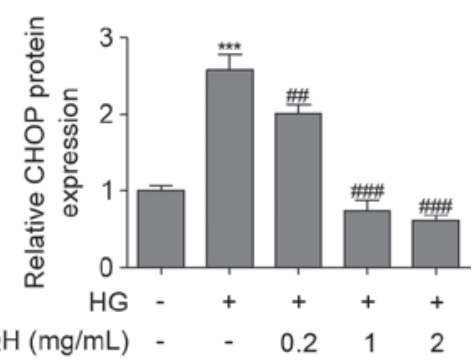

Figure 3. HQH inhibits HG-induced GRP78 and CHOP in podocytes. (A) mRNA and (B) protein expression levels of GRP78 were measured using RT-PCR and western blot analyses, respectively, following $24 \mathrm{~h}$ treatment. The (C) mRNA and (D) protein expression levels of CHOP were measured using RT-PCR and western blot analyses, respectively, following $24 \mathrm{~h}$ treatment. Values are expressed as the mean \pm standard deviation ( $\mathrm{n}=3$ in each group). ${ }^{* * *} \mathrm{P}<0.001$, vs. control group; ${ }^{\# \#} \mathrm{P}<0.01$ and ${ }^{\# \# \#} \mathrm{P}<0.001$, vs. HG only treatment group. HG, high glucose; HQH, Huaiqihuang; RT-PCR, reverse transcription-polymerase chain reaction; CHOP C/EBP-homologous protein; GRP78, glucose-related protein 78.

potential, compared with that in the control group. HG in combination with HQH significantly improved mitochondrial membrane potential in the podocytes. The effect of HG on the mobilization of $\mathrm{Ca}^{2+}$ was then assessed. When podocytes were treated with $\mathrm{HG}$, the $\mathrm{Ca}^{2+}$ levels were significantly increased, compared with those in the control group, however, treatment of podocytes with $\mathrm{HQH}$ significantly reversed the $\mathrm{HG}$-induced upregulation of $\mathrm{Ca}^{2+}$ (Fig. 2E).

HQH inhibits HG-induced GRP78 and CHOP in podocytes. GRP78, an important molecular chaperone localized in the ER, is used as an indicator of ER stress (22). Compared with untreated podocytes, GRP78 was increased in the HG single treatment group, at the mRNA and protein levels (Fig. 3A and B). Previous studies have demonstrated the importance of CHOP in ER stress-induced cell death (16). Consistent with this, $\mathrm{HG}$ treatment in the present study resulted in a significant increase in the mRNA and protein expression of CHOP in podocytes (Fig. 3C and D). These results demonstrated that ER stress was activated in the HG-treated podocytes. Of note, treatment of the podocytes with HQH significantly reversed the HG-induced upregulation of GRP78 (Fig. 3A and B) and CHOP (Fig. 3C and D).

GRP78 loss-of-function attenuates $H G$-induced podocyte dysfunction. To further investigate whether HG-induced podocyte dysfunction occurred due to the activation of GRP78, GRP78 siRNA was used. The transfection of podocytes with GRP78 siRNA specifically inhibited the expression of GRP78 (Fig. 4A). In addition, GRP78 siRNA reduced the HG-induced upregulation of caspase 3 (Fig. 4B) and the protein expression of cleaved-caspase3 in podocytes (Fig. 4C). Furthermore, GRP78 siRNA inhibited HG-induced cell apoptosis (Fig. 4D). DNA damage has been found in podocytes with induced injury (9). In the present study, the tail length in the HG-treated group was markedly longer, compared with that in the control group. However, the tail length was significantly suppressed by GRP78 loss-of-function (Fig. 4E). These results suggested that GRP78 loss-of-function alleviated the podocyte dysfunction induced by $\mathrm{HG}$.

\section{Discussion}

In the present study, it was determined that cell viability and the expression of nephrin decreased in cultured podocytes exposed to HG (30 mM). The results also demonstrated that HG induced ROS generation, mitochondrial dysfunction and ER stress in podocytes. Simultaneously, HG treatment resulted in a significant increase in the mRNA and protein expression of GRP78 and CHOP in podocytes. HQH was found to reverse HG-induced ROS generation, mitochondrial dysfunction, ER stress and the upregulated expression of GRP78 and CHOP, and GRP78 loss-of-function alleviate the podocyte dysfunction, which was induced by HG. It was concluded that $\mathrm{HQH}$ may act as a potential therapeutic drug for HG-induced podocyte dysfunction.

Mitochondrial dysfunction has been implicated in several major diseases, including glomerular diseases (23). Mitochondria maintain cellular redox and energy homeostasis, and are a major source of intracellular ROS production. Mitochondrial ROS accumulation may contribute to stress-induced mitochondrial dysfunction and apoptosis, and thereby to glomerulosclerosis $(24,25)$. Previous studies have indicated that elevated levels of saturated free fatty acid are harmful to mouse podocytes following mitochondrial oxidative stress (9). Aldosterone-induced injury has been found to decrease the expression of peroxisome proliferator-activated receptor- $\gamma$ coactivator $1 \alpha$, and induce mitochondrial and 


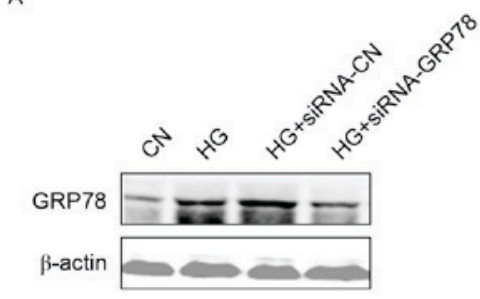

C
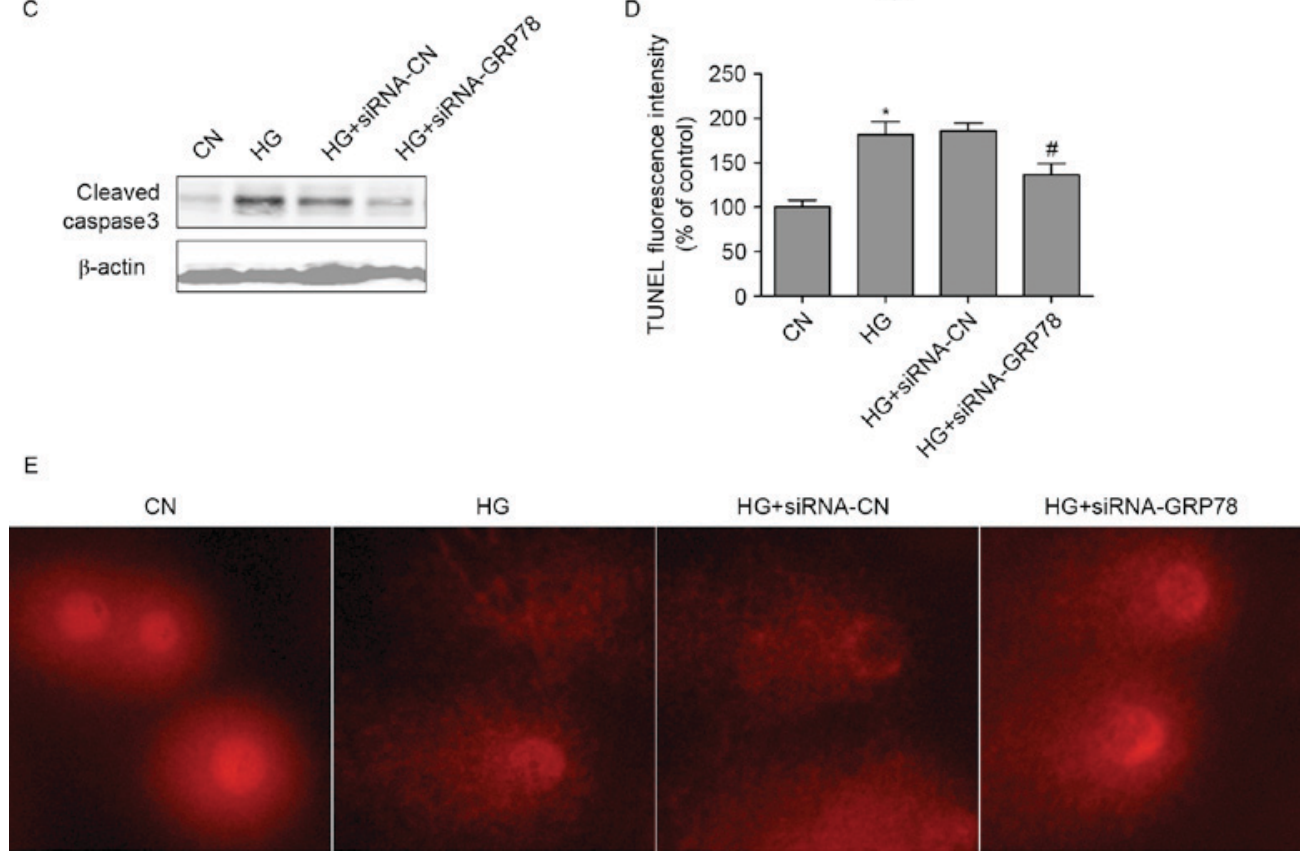

B

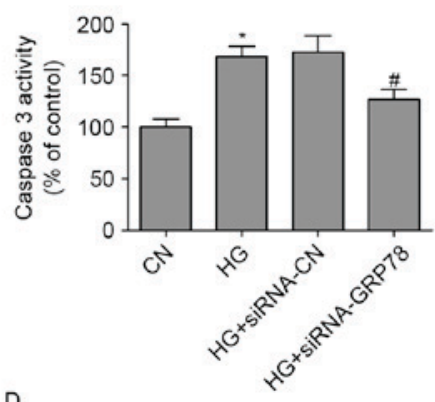

D

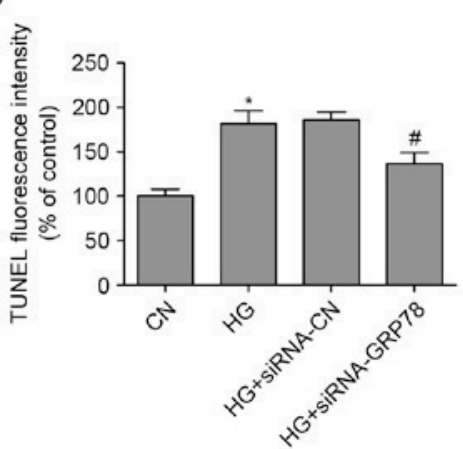

Figure 4. GRP78 loss-of-function attenuates HG-induced podocyte dysfunction. Cells were transfected with GRP78 or control siRNA for 24 h, and incubated with or without HG (30 mM) for 24 h. (A) Expression of GRP78 was examined using western blot analysis. (B) Levels of caspase 3 were measured using ELISA analysis. (C) Expression of cleaved-caspase3 was examined using western blot analysis. (D) TUNEL-positive (apoptotic) cells were measured using flow cytometry. (E) DNA damage was measured using a comet assay. Photomicrographs were captured under $\mathrm{x} 200 \mathrm{magnification}$. Values are expressed as the mean \pm standard deviation ( $\mathrm{n}=3$ in each group). ${ }^{*} \mathrm{P}<0.05$, vs control group; ${ }^{\sharp} \mathrm{P}<0.05$, vs. HG+siRNA-CN group. HG, high glucose; HQH, Huaiqihuang; siRNA, small interfering RNA; TUNEL, terminal deoxynucleotidyl transfrase-mediated deoxyuridine triphosphate nick end labeling; GRP78, glucose-related protein 78; CN, control.

podocyte damage in a dose- and time-dependent manner (26). These results suggest that mitochondrial dysfunction is involved in toxin-induced podocyte dysfunction. Two major events have been reported in apoptosis involving mitochondrial dysfunction. One is the alteration in membrane permeability and the subsequent loss of membrane potential; the other is the release of apoptotic proteins, including cytochrome $c$, from the intermembrane space of mitochondria into the cytosol $(27,28)$. In the present study, it was found that treatment of podocytes with HG induced the loss of the mitochondrial membrane potential. However, HQH significantly improved mitochondrial membrane potential in HG-induced podocyte mitochondrial dysfunction. When the podocytes were treated with $\mathrm{HG}$, the levels of $\mathrm{Ca}^{2+}$ were significantly increased, compared with those in the control group, whereas treatment of podocytes with $\mathrm{HQH}$ significantly reversed the HG-induced upregulation of $\mathrm{Ca}^{2+}$.

The ER is critical in controlling the fate of cells and is a dynamic organelle responsible for multiple cellular functions $(9,16)$. An increasing number of studies have demonstrated that ER stress is key in the pathogenesis of podocyte dysfunction $(9,11,29)$. In diabetic rats, ER stress-induced podocyte apoptosis has been found to be associated with upregulation of the mRNA and protein expression levels of GRP78 (30). Palmitate can induce podocyte apoptosis via ER stress, and the expression of GRP78 is significantly increased when exposed to palmitate (31). GRP78, a $78 \mathrm{kDa}$ glucose-regulated protein, is a major ER chaperone, which is critical in regulating ER, and its upregulation has been suggested to increase the capacity to buffer stressful insults initiating from ER (13). In the present study, GRP78 was increased in the HG single treatment group, at the mRNA and protein levels. Treatment of podocytes with $\mathrm{HQH}$ significantly reversed the HG-induced upregulation of GRP78. In addition, treatment of podocytes with $\mathrm{HQH}$ significantly reversed the $\mathrm{HG}$-induced upregulation of CHOP. CHOP is a nuclear protein, which forms stable heterodimers with $\mathrm{C} / \mathrm{EBP}$ family members and is induced in response to ER stress (32).

In conclusion, the present study demonstrated that $\mathrm{HG}$ was able to exert mitochondrial dysfunction and ER stress 
in podocytes. The results showed that HQH suppressed HG-induced cell apoptosis, mitochondrial dysfunction and ER stress in the podocytes. These findings provide a novel explanation for the direct anti-apoptotic effects of $\mathrm{HQH}$, which may have a potential protective effect against $\mathrm{HG}$-induced podocyte dysfunction.

\section{Acknowledgements}

The present study was supported by the Public Projects of Zhejiang Province (grant no. 2012C33048).

\section{References}

1. Weir MR: Salt, hypertension, and proteinuria in diabetic nephropathy. Lancet Diabetes Endocrinol 2: 351-352, 2014.

2. Dong C, Zheng H, Huang S, You N, Xu J, Ye X, Zhu Q, Feng Y, You Q, Miao H, et al: Heme oxygenase-1 enhances autophagy in podocytes as a protective mechanism against high glucose-induced apoptosis. Exp Cell Res 337: 146-159, 2015.

3. Jefferson JA, Shankland SJ and Pichler RH: Proteinuria in diabetic kidney disease: A mechanistic viewpoint. Kidney Int 74: 22-36, 2008

4. Wolf G, Chen S and Ziyadeh FN: From the periphery of the glomerular capillary wall toward the center of disease: Podocyte injury comes of age in diabetic nephropathy. Diabetes 54: 1626-1634, 2005.

5. Lemley KV, Lafayette RA, Safai M, Derby G, Blouch K, Squarer A and Myers BD: Podocytopenia and disease severity in IgA nephropathy. Kidney Int 61: 1475-1485, 2002.

6. Meyer TW, Bennett PH and Nelson RG: Podocyte number predicts long-term urinary albumin excretion in Pima Indians with Type II diabetes and microalbuminuria. Diabetologia 42: 1341-1344, 1999.

7. Menini S, Iacobini C, Oddi G, Ricci C, Simonelli P, Fallucca S, Grattarola M, Pugliese F, Pesce C and Pugliese G: Increased glomerular cell (podocyte) apoptosis in rats with streptozotocin-induced diabetes mellitus: Role in the development of diabetic glomerular disease. Diabetologia 50: 2591-2599, 2007.

8. Han SY, Kang YS, Jee YH, Han KH, Cha DR, Kang SW and Han DS: High glucose and angiotensin II increase betal integrin and integrin-linked kinase synthesis in cultured mouse podocytes. Cell Tissue Res 323: 321-332, 2006.

9. Xu S, Nam SM, Kim JH, Das R, Choi SK, Nguyen TT, Quan X, Choi SJ, Chung CH, Lee EY, et al: Palmitate induces ER calcium depletion and apoptosis in mouse podocytes subsequent to mitochondrial oxidative stress. Cell Death Dis 6: e1976, 2015.

10. Pereira ER, Frudd K, Awad W and Hendershot LM: Endoplasmic reticulum (ER) stress and hypoxia response pathways interact to potentiate hypoxia-inducible factor 1 (HIF-1) transcriptional activity on targets like vascular endothelial growth factor (VEGF). J Biol Chem 289: 3352-3364, 2014.

11. Zode GS, Sharma AB, Lin X, Searby CC, Bugge K, Kim GH, Clark AF and Sheffield VC: Ocular-specific ER stress reduction rescues glaucoma in murine glucocorticoid-induced glaucoma. J Clin Invest 124: 1956-1965, 2014.

12. Zhu Q, Guo R, Liu C, Fu D, Liu F, Hu J and Jiang H: Endoplasmic reticulum stress-mediated apoptosis contributing to high glucose-induced vascular smooth muscle cell calcification. J Vasc Res 52: 291-298, 2015.

13. Chen YJ, Wu CL, Liu JF, Fong YC, Hsu SF, Li TM, Su YC, Liu SH and Tang CH: Honokiol induces cell apoptosis in human chondrosarcoma cells through mitochondrial dysfunction and endoplasmic reticulum stress. Cancer Lett 291: 20-30, 2010.

14. Ha TS, Park HY, Seong SB and Ahn HY: Angiotensin II induces endoplasmic reticulum stress in podocyte, which would be further augmented by PI3-kinase inhibition. Clin Hypertens 21: 13,2015 .
15. Cao Y, Hao Y, Li H, Liu Q, Gao F, Liu W and Duan H: Role of endoplasmic reticulum stress in apoptosis of differentiated mouse podocytes induced by high glucose. Int J Mol Med 33: 809-816, 2014.

16. Wang ZS, Xiong F, Xie XH, Chen D, Pan JH and Cheng L: Astragaloside IV attenuates proteinuria in streptozotocin-induced diabetic nephropathy via the inhibition of endoplasmic reticulum stress. BMC Nephrol 16: 44, 2015.

17. Liu H, Sun W, Gu LB, Tu Y, Yu BY and Hu H: Huaiqihuang Granules () reduce proteinuria by enhancing nephrin expression and regulating necrosis factor $\kappa \mathrm{B}$ signaling pathway in adriamycin-induced nephropathy. Chin J Integr Med, 2015.

18. Sun W, Zhu Z, Yu J, Wang YH, Xiong M, Gao X, Zhao ZH and Liu XG: Effects of Chinese herbal medicine Huaiqihuang Granule on nephrin and podocin expressions in renal tissues of rats with adriamycin-induced nephrosis. Zhong Xi Yi Jie He Xue Bao 9: 546-552, 2011 (In Chinese).

19. Li CX, Xia M, Han WQ, Li XX, Zhang C, Boini KM, Liu XC and Li PL: Reversal by growth hormone of homocysteine-induced epithelial-to-mesenchymal transition through membrane raft-redox signaling in podocytes. Cell Physiol Biochem 27: 691-702, 2011.

20. Livak KJ and Schmittgen TD: Analysis of relative gene expression data using real-time quantitative PCR and the 2(-Delta Delta C(T)) method. Methods 25: 402-408, 2001.

21. Ruotsalainen V, Ljungberg P, Wartiovaara J, Lenkkeri U, Kestilä M, Jalanko H, Holmberg C and Tryggvason K: Nephrin is specifically located at the slit diaphragm of glomerular podocytes. Proc Natl Acad Sci USA 96: 7962-7967, 1999.

22. Chen Y, Liu CP, Xu KF, Mao XD, Lu YB, Fang L, Yang JW and Liu C: Effect of taurine-conjugated ursodeoxycholic acid on endoplasmic reticulum stress and apoptosis induced by advanced glycation end products in cultured mouse podocytes. Am J Nephrol 28: 1014-1022, 2008

23. Casalena G, Krick S, Daehn I, Yu L, Ju W, Shi S, Tsai SY, D'Agati V, Lindenmeyer M, Cohen CD, et al: Mpv17 in mitochondria protects podocytes against mitochondrial dysfunction and apoptosis in vivo and in vitro. Am J Physiol Renal Physiol 306: F1372-F1380, 2014.

24. Daehn I, Casalena G, Zhang T, Shi S, Fenninger F, Barasch N, Yu L, D'Agati V, Schlondorff D, Kriz W, et al: Endothelial mitochondrial oxidative stress determines podocyte depletion in segmental glomerulosclerosis. J Clin Invest 124: 1608-1621, 2014.

25. Zhu C, Xuan X, Che R, Ding G, Zhao M, Bai M, Jia Z, Huang S and Zhang A: Dysfunction of the PGC-1 $\alpha$-mitochondria axis confers adriamycin-induced podocyte injury. Am J Physiol Renal Physiol 306: F1410-F1417, 2014.

26. Yuan Y, Huang S, Wang W, Wang Y, Zhang P, Zhu C, Ding G, Liu B, Yang T and Zhang A: Activation of peroxisome proliferator-activated receptor- $\gamma$ coactivator $1 \alpha$ ameliorates mitochondrial dysfunction and protects podocytes from aldosterone-induced injury. Kidney Int 82: 771-789, 2012.

27. Zamzami N, Brenner C, Marzo I, Susin SA and Kroemer G: Subcellular and submitochondrial mode of action of Bcl-2-like oncoproteins. Oncogene 16: 2265-2282, 1998.

28. Liu X, Kim CN, Yang J, Jemmerson R and Wang X: Induction of apoptotic program in cell-free extracts: Requirement for dATP and cytochrome c. Cell 86: 147-157, 1996.

29. Yuan Y, Xu X,Zhao C, Zhao M, Wang H,Zhang B, Wang N, Mao H, Zhang A and Xing C: The roles of oxidative stress, endoplasmic reticulum stress, and autophagy in aldosterone/mineralocorticoid receptor-induced podocyte injury. Lab Invest 95: 1374-1386, 2015.

30. Chen Y, Gui D, Chen J, He D, Luo Y and Wang N: Down-regulation of PERK-ATF4-CHOP pathway by Astragaloside IV is associated with the inhibition of endoplasmic reticulum stress-induced podocyte apoptosis in diabetic rats. Cell Physiol Biochem 33: 1975-1987, 2014.

31. Tao JL, Wen YB, Shi BY, Zhang H, Ruan XZ, Li H, Li XM, Dong WJ and Li XW: Endoplasmic reticulum stress is involved in podocyte apoptosis induced by saturated fatty acid palmitate. Chin Med J (Engl) 125: 3137-3142, 2012.

32. Wang XZ, Lawson B, Brewer JW, Zinszner H, Sanjay A, Mi LJ, Boorstein R, Kreibich G,Hendershot LM and Ron D: Signals from the stressed endoplasmic reticulum induce C/EBP-homologous protein (CHOP/GADD153). Mol Cell Biol 16: 4273-4280, 1996. 